\title{
Endoscopic endonasal optic nerve and orbital apex decompression for nontraumatic optic neuropathy: surgical nuances and review of the literature
}

\author{
Moncef Berhouma, M.D., M.Sc., ${ }^{1}$ Timothee Jacquesson, M.D., M.Sc., ${ }^{1,2}$ \\ Lucie Abouaf, M.D., M.Sc., ${ }^{2,3}$ Alain Vighetto, M.D., Ph.D., ${ }^{2,3}$ \\ and Emmanuel Jouanneau, M.D., Ph.D., ${ }^{1,2,4}$ \\ ${ }^{I}$ Skull Base Surgery Unit, Department of Neurosurgery B, and ${ }^{3}$ Department of Neuro-ophthalmology, Pierre \\ Wertheimer Neurological and Neurosurgical Hospital, Hospices Civils de Lyon; ${ }^{2}$ Research and Education \\ Unit of Medicine, Claude Bernard University Lyon 1; and ${ }^{4}$ INSERM U1028, CNRS UMR5292, \\ Neurosciences Research Center of Lyon, Neuro-oncology and Neuro-inflammation Team, Lyon, France
}

Object. While several approaches have been described for optic nerve decompression, the endoscopic endonasal route is gaining favor because it provides excellent exposure of the optic canal and the orbital apex in a minimally invasive manner. Very few studies have detailed the experience with nontraumatic optic nerve decompressions, whereas traumatic cases have been widely documented. Herein, the authors describe their preliminary experience with endoscopic endonasal decompression for nontraumatic optic neuropathies (NONs) to determine the procedure's efficacy and delineate its potential indications and limits.

Methods. The medical reports of patients who had undergone endoscopic endonasal optic nerve and orbital apex decompression for NONs at the Lyon University Neurosurgical Hospital in the period from January 2012 to March 2014 were reviewed. For all cases, clinical and imaging data on the underlying pathology and the patient, including demographics, preoperative and 6-month postoperative ophthalmological assessment results, symptom duration, operative details with video debriefing, as well as the immediate and delayed postoperative course, were collected from the medical records.

Results. Eleven patients underwent endoscopic endonasal decompression for NON in the multidisciplinary skull base surgery unit of the Lyon University Neurosurgical Hospital during the 27-month study period. The mean patient age was 53.4 years, and there was a clear female predominance ( 8 females and 3 males). Among the underlying pathologies were 4 sphenoorbital meningiomas (36\%), 3 optic nerve meningiomas (27\%), and 1 each of trigeminal neuroma (9\%), orbital apex meningioma (9\%), ossifying fibroma (9\%), and inflammatory pseudotumor of the orbit (9\%). Fifty-four percent of the patients had improved visual acuity at the 6-month follow-up. Only 1 patient whose sphenoorbital meningioma had been treated at the optic nerve atrophy stage continued to worsen despite surgical decompression. The 2 patients presenting with preoperative papilledema totally recovered. One case of postoperative epistaxis was successfully treated using balloon inflation, and 1 case of air swelling of the orbit spontaneously resolved.

Conclusions. Endoscopic endonasal optic nerve decompression is a safe, effective, and minimally invasive technique affording the restoration of visual function in patients with nontraumatic compressive processes of the orbital apex and optic nerve. The timing of decompression remains crucial, and patients should undergo such a procedure early in the disease course before optic atrophy.

(http://thejns.org/doi/abs/10.3171/2014.7.FOCUS14303)

KEY WORDS $\bullet \quad$ skull base surgery $\bullet \quad$ minimally invasive neurosurgery $\bullet$
endoscopic endonasal surgery $\bullet \quad$ optic nerve decompression $\bullet \quad$ orbital tumors
optic neuropathy

A LTHOUGH several surgical approaches have been historically described for optic nerve decompression, ${ }^{4}$ the endoscopic endonasal technique is gaining popularity in the skull base surgeon's armamentarium. $1,7,10,14,26,36,43,58$ This technique definitely provides excellent exposure of the optic canal and orbital apex in a minimally invasive fashion. While decompression in

Abbreviations used in this paper: $\mathrm{NON}=$ nontraumatic optic neuropathy; TOF = time-of-flight. traumatic optic neuropathy has been widely investigated, ${ }^{11,13,18-20,24,28,29,36,37,40,47,48,52-59,61}$ indeed with debatable results, decompression for nontraumatic optic neuropathies (NONs) is still insufficiently studied. 2,3,5,12,15,17,21-23,25-27,33,35, $36,39,41,42,45,46,51$ We hypothesize that the minimally invasive endoscopic endonasal approach will be more widely used in decompressions for nontraumatic pathologies of the orbital apex. We present our preliminary series of 11 optic nerve decompressions performed for NONs. The surgical technique is detailed and potential indications are discussed. 


\section{Methods}

\section{Patient Cohort}

We reviewed the medical records of all patients who had undergone endoscopic endonasal decompression for NONs at the Lyon University Neurosurgical Hospital in the period from January 2012 to March 2014. Data were collected from preoperative and postoperative ophthalmological examinations, operative reports, and hospital records.

\section{Surgical Management}

Preoperative orbital MR images and thin-slice bone CT scans were reviewed to determine the most appropriate surgical approach and the precise anatomy of the sphenoethmoidal complex (the Onodi cells, septa, bone thickness, and so forth). The surgical procedure was standardized, involving advanced endoscopic techniques derived from pituitary surgery and intraoperative navigation systems coupling CT and MRI data.

\section{Data Collection}

For all cases, clinical and imaging data on the underlying pathology and the patient, including demographics, pre- and postoperative ophthalmological assessment results, symptom duration, operative details with video debriefing, as well as the immediate and delayed postoperative course, were collected from the medical records. The ophthalmological assessment included visual acuity testing according to the decimal scale of Monoyer, a fundoscopic examination, and computerized visual field testing.

\section{Literature Review}

An exhaustive and systematic review of the literature was performed using large biomedical databases (PubMed, Google Scholar, ScienceDirect, and Scopus) and the key words "optic nerve," "orbital apex," "decompression," "optic neuropathy," "endoscopic endonasal," and "minimally invasive neurosurgery."

\section{Results}

\section{Patient Characteristics}

Eleven patients underwent endoscopic endonasal decompression for NON in the multidisciplinary skull base surgery unit of the Lyon University Neurosurgical Hospital during the 27-month study period (Table 1). The mean patient age was 53.4 years, and there was a clear female predominance (8 females and 3 males). Among the underlying pathologies were 4 sphenoorbital meningiomas (36\%), 3 optic nerve meningiomas (27\%), and 1 each of trigeminal neuroma (9\%), orbital apex meningioma (9\%), ossifying fibroma (9\%), and inflammatory pseudotumor of the orbit $(9 \%)$.

\section{Surgical Technique}

Of the 11 patients, 4 underwent a secondary surgical procedure for the underlying pathology between 3 and 6 months after the optic nerve decompression: One orbital meningioma was secondarily totally resected through an intracranial subfrontal craniotomy, and 3 sphenoorbital meningiomas were resected in a classic frontotemporal manner. Two patients did benefit from a single procedure: one with a trigeminal neuroma removed through an anteromedial corridor to Meckel's cave and one with an ossifying fibroma of the medial orbital apex.

\section{Visual Outcome}

Fifty-four percent of the patients had improved visual acuity at the 6-month follow-up. Only 1 patient (9\%) whose sphenoorbital meningioma had been treated at the optic nerve atrophy stage continued to worsen despite surgical decompression. The 2 patients presenting with preoperative papilledema totally recovered. Four patients (36.4\%) remained stable or improved slightly $(<2 / 10$ of an increase on the visual acuity scale).

\section{Postoperative Complications}

One patient presented with a moderate epistaxis on the 3rd postoperative day, requiring a compressive inflatable balloon for 48 hours. A second patient experienced swelling of the orbit by air insufflated during sneezing on the 2nd postoperative day, which spontaneously resolved within 1 week.

\section{Illustrative Cases}

\section{Case 3}

A 64-year-old man, whose medical history included chronic leukemia treated with chemotherapy, was admitted for 6 months of progressive visual decline in the left eye and left frontoorbital dysesthesias. Visual assessment revealed deficient left visual acuity (counts fingers at 50 $\mathrm{cm}$ ), decreased color vision, and an afferent pupillary defect. Fundoscopy revealed left papillary pallor. Three-dimensional time-of-flight (TOF) MRI (Fig. 1A) showed an enhancing lesion of the left orbital apex following the trajectory of the superior orbital fissure. Because of the facial dysesthesia, a diagnosis of trigeminal neuroma was discussed, even though a metastatic lesion due to the chronic leukemia could not be eliminated in this context. With the patient under general anesthesia and the aid of image guidance, we approached the lesion via a left sphenoethmoidal approach. After performing a wide opening of the left posterior ethmoidal cells, including the Onodi cell, we identified the left optic canal, as well as the anteromedial wall of the left Meckel's cave lateral to the left internal carotid artery (Fig. 1B). The left lamina papyracea was then easily outfractured using a blunt microspatula, and the optic canal was drilled from lateral to medial under thorough saline irrigation. The thin eggshell bone remaining on the optic nerve was removed at approximately $270^{\circ}$ until pulsations of the optic nerve sheath were observed (Fig. $1 \mathrm{C}$ and $\mathrm{D})$. The tumor was subsequently removed through the anteromedial wall of Meckel's cave. Histopathological examination confirmed the diagnosis of trigeminal neuroma. The postoperative course was uneventful, and visual acuity was stable. At the 6-month follow-up, a slight left facial dysesthesia remained, left visual acuity improved to $6 / 10$, and no tumor recurrence was noted. 


\section{Endoscopic endonasal optic nerve decompression}

TABLE 1: Summary of characteristics in 11 patients who underwent endoscopic endonasal optic nerve and orbital apex decompressions between 2012 and 2014*

\begin{tabular}{|c|c|c|c|c|c|c|c|c|}
\hline \multirow{2}{*}{$\begin{array}{l}\text { Case } \\
\text { No. }\end{array}$} & \multirow{2}{*}{$\begin{array}{l}\text { Sex, Age } \\
\quad(y r s)\end{array}$} & \multirow[b]{2}{*}{ Underlying Pathology } & \multicolumn{2}{|c|}{ Visual Acuity } & \multirow{2}{*}{$\begin{array}{l}\text { Visual Field } \\
\text { Assessment }\end{array}$} & \multicolumn{2}{|c|}{ Funduscopy } & \multirow{2}{*}{$\begin{array}{l}\text { Complementary } \\
\text { Management }\end{array}$} \\
\hline & & & Preop & Postop & & Preop & Postop & \\
\hline 1 & $F, 52$ & LON meningioma & LP & $2 / 10$ & $\begin{array}{l}\text { stable concentric } \\
\quad \text { deficit }\end{array}$ & papillary pallor & papillary pallor & radiotherapy \\
\hline 2 & $\mathrm{~F}, 49$ & SpO meningioma & $4 / 10$ & $7 / 10$ & improvement & papillary pallor & papillary pallor & follow-up \\
\hline 3 & $M, 64$ & trigeminal neuroma & CF50 & $6 / 10$ & improvement & papillary pallor & papillary pallor & $\begin{array}{l}\text { removal during same } \\
\text { procedure }\end{array}$ \\
\hline 4 & $\mathrm{~F}, 67$ & LON meningioma & CF10 & CF10 & $\begin{array}{l}\text { stable temporal } \\
\text { deficit }\end{array}$ & papillary atrophy & papillary atrophy & radiotherapy \\
\hline 5 & $F, 56$ & SpO meningioma & $1 / 10$ & $3 / 10$ & $\begin{array}{l}\text { stable concentric } \\
\quad \text { deficit }\end{array}$ & papillary pallor & papillary pallor & $\begin{array}{l}\text { secondary surgical } \\
\text { removal }\end{array}$ \\
\hline 6 & $\mathrm{~F}, 60$ & LON meningioma & $7 / 10$ & $10 / 10$ & improvement & normal & normal & radiotherapy \\
\hline 7 & $\mathrm{~F}, 30$ & orbital apex meningioma & $8 / 10$ & $9 / 10$ & normal & papilledema Grade 2 & normal & $\begin{array}{l}\text { secondary surgical } \\
\text { removal }\end{array}$ \\
\hline 8 & $F, 68$ & inflammatory pseudotumor & CF10 & $8 / 10$ & normal & papilledema Grade 1 & normal & follow-up \\
\hline 9 & M, 27 & ossifying fibroma & $7 / 10$ & $8 / 10$ & normal & normal & normal & $\begin{array}{l}\text { removal during same } \\
\text { procedure }\end{array}$ \\
\hline 10 & M, 61 & SpO meningioma & $6 / 10$ & $4 / 10$ & $\begin{array}{l}\text { stable temporal } \\
\text { deficit }\end{array}$ & papillary atrophy & papillary atrophy & $\begin{array}{l}\text { secondary surgical } \\
\text { removal }\end{array}$ \\
\hline 11 & $F, 54$ & SpO meningioma & $7 / 10$ & $8 / 10$ & normal & normal & normal & $\begin{array}{l}\text { secondary surgical } \\
\text { removal }\end{array}$ \\
\hline
\end{tabular}

\footnotetext{
* All postoperative assessments were performed at the 6th postoperative month except for the patient in Case 11, who was evaluated at the 3rd month
} (most recent patient). $\mathrm{CF} 10=$ counts fingers at $10 \mathrm{~cm} ; \mathrm{CF} 50=$ counts fingers at $50 \mathrm{~cm} ; \mathrm{LON}=$ left optic nerve; $\mathrm{LP}=$ light perception; $\mathrm{SpO}=\mathrm{sphenoorbital}$.

\section{Case 9}

A 27-year-old man without any remarkable medical history presented with progressive left proptosis and slight visual decline in the left eye. Visual acuity reached 10/10 in the right eye and 7/10 in the left, with no anomalies on fundoscopic examination and visual field testing. Imaging revealed a calcified nonenhancing tumor of the left medial orbital wall and optic canal, suggesting an ossifying fibroma (Fig. 2A). An endoscopic endonasal approach via the left nostril (Fig. 2B) was performed, allowing subtotal removal of a crumbly osseous tumor using a piecemeal technique along with irrigated ultrasonic drilling. The medial orbital wall and apex were drilled until the periorbital layer was reached. The left optic canal was consequently opened from lateral to medial (Fig. 2C). The postoperative course was uneventful. The diagnosis of benign ossifying fibroma was definitively established. Follow-up evaluation at 6 months after treatment confirmed an improvement in left visual acuity that reached $8 / 10$ and a reduction in the proptosis. Computed tomography scanning showed good decompression of the orbital apex and optic canal (Fig. 2D), as well as an anterior medial remnant, which is being monitored yearly in the absence of any symptoms except a slight proptosis.

\section{Discussion}

Optic nerve decompression has been thoroughly described for traumatic optic neuropathy. ${ }^{23,29,50,57}$ Nontraumatic optic neuropathy is a rare condition that can be caused by a variety of disorders, including tumors, endocrine orbitopathy, idiopathic intracranial hypertension, bone dysplasia, or infectious processes (Table 2). Therefore, surgical decompression of the optic nerve may be either part of the treatment for the primary compressive process (for example, an orbital apex tumor) or a preliminary step before treating the underlying cause via an intracranial route (for example, sphenoorbital meningioma).

Various surgical approaches ${ }^{4}$ have been described for decompression of the optic nerve: a medial approach by external ethmoidectomy, an inferomedial approach via a transantral transethmoidal route, a supraorbital transcranial approach, and the endoscopic endonasal transsphenoethmoidal approach. This latter approach affords excellent visualization of the optic canal and medial orbital apex with minimal morbidity and no brain retraction or scarring. Nevertheless, the optimal timing and the visual benefits are still questioned in the absence of a prospective study. ${ }^{41}$

\section{Surgical Anatomy}

Considered as an extension of the brain, each optic nerve is enveloped by 3 meningeal layers (Figs. 3-6). ${ }^{8,16,60}$ Each measures about $50 \mathrm{~mm}$ in length. Four anatomical segments can be described: intraocular $(1 \mathrm{~mm})$, intraorbital $(25-30 \mathrm{~mm})$, intracanalicular $(10 \mathrm{~mm})$, which is the most vulnerable to compression, and intracranial $(10 \mathrm{~mm})$. It is the intracanalicular segment that is addressed in endoscopic endonasal decompression. In this segment the optic nerve is fixed by the fibrous annulus of Zinn. From 

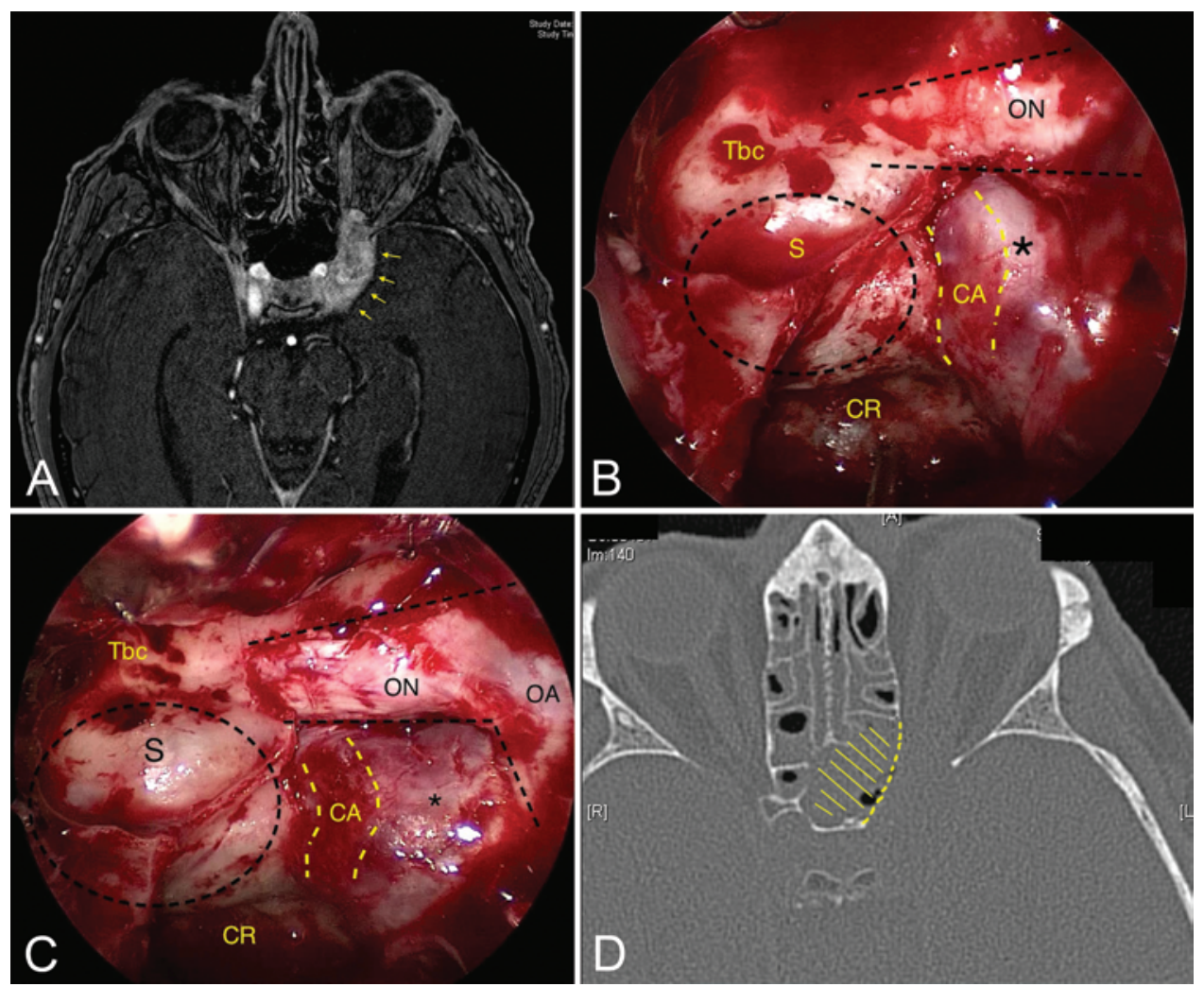

FIG. 1. Case 3. A: Axial 3D TOF high-resolution T1-weighted MR sequence with Gd showing trigeminal neuroma (yellow arrows) of the left orbital apex. B: Endoscopic view through the left nostril after sphenoidotomy and posterior ethmoidectomy. Asterisk indicates the anteromedial corridor to the left Meckel's cave. Black and yellow dotted lines mark the borders of the structure indicated. C: View after a lateral to medial decompression of the left orbital apex and optic nerve, before trigeminal neuroma removal. Asterisk indicates the anteromedial corridor to the left Meckel's cave. Black and yellow dotted lines mark the borders of the structure indicated. D: Postoperative CT scan showing the extent of left optic canal and orbital apex decompression (dotted and solid yellow lines). $\mathrm{CA}=$ internal carotid artery; $\mathrm{CR}=$ clival recess; $\mathrm{OA}=$ orbital apex; $\mathrm{ON}=$ left optic nerve within its canal; $\mathrm{S}=$ sella turcica; $\mathrm{Tbc}=$ tuberculum sellae.

the endoscopic endonasal view, the optic nerve is covered by a thin bone of about one-half millimeter in the majority of patients and is uncovered in $4 \%$ of patients. In comparison, the carotid artery is uncovered in the sphenoid sinus in about $8 \%$ of patients. These conditions are of paramount importance during drilling of the optic canal.
The optic canal is fashioned from the 2 struts of the lesser wing of the sphenoid bone. It contains the optic nerve and the ophthalmic artery. This canal is approximately $10 \mathrm{~mm}$ long and $4-5 \mathrm{~mm}$ wide. It is thinner and wider proximally and thicker and narrower distally. At this point, the dura mater and the periosteal layer of the

TABLE 2: Summary of published series on endoscopic endonasal optic nerve and orbital apex decompression for NON during the last 10 years*

\begin{tabular}{|c|c|c|c|c|c|}
\hline Authors \& Year & $\begin{array}{l}\text { No. of } \\
\text { Patients }\end{array}$ & $\begin{array}{l}\text { Mean Age } \\
\quad(y r s)\end{array}$ & Underlying Pathology & Complication & $\begin{array}{l}\% \text { w/ Good } \\
\text { Visual } \\
\text { Outcome }\end{array}$ \\
\hline Lund \& Rose, 2006 & 12 & 42.6 & sphenoid wing meningioma & no & 58.3 \\
\hline $\begin{array}{l}\text { Pletcher \& Metson, } \\
\quad 2007\end{array}$ & $\begin{array}{l}7 \text { (10 decom- } \\
\text { pressions) }\end{array}$ & 49 & $\begin{array}{l}\text { meningioma, lymphangioma, mucocele, } \\
\text { fibrous dysplasia, Graves' orbitopathy }\end{array}$ & $\begin{array}{l}\text { postop hyponatremia, } \\
\text { corneal abrasions }\end{array}$ & 70 \\
\hline Attia et al., 2012 & 8 & NA & suprasellar meningioma & no & 37.5 \\
\hline Sencer et al., 2014 & 10 & 34.1 & idiopathic intracranial hypertension & no & 80 \\
\hline current study & 11 & 53.4 & $\begin{array}{l}\text { sphenoorbital meningioma, optic nerve } \\
\text { meningioma, orbital meningioma, in- } \\
\text { flammatory pseudotumor, ossifying } \\
\text { fibroma, trigeminal neuroma }\end{array}$ & epistaxis, pneumo-orbit & 54.5 \\
\hline
\end{tabular}

\footnotetext{
* Series dealing with traumatic optic neuropathy or including fewer than 3 patients were excluded. NA = not available.
} 


\section{Endoscopic endonasal optic nerve decompression}
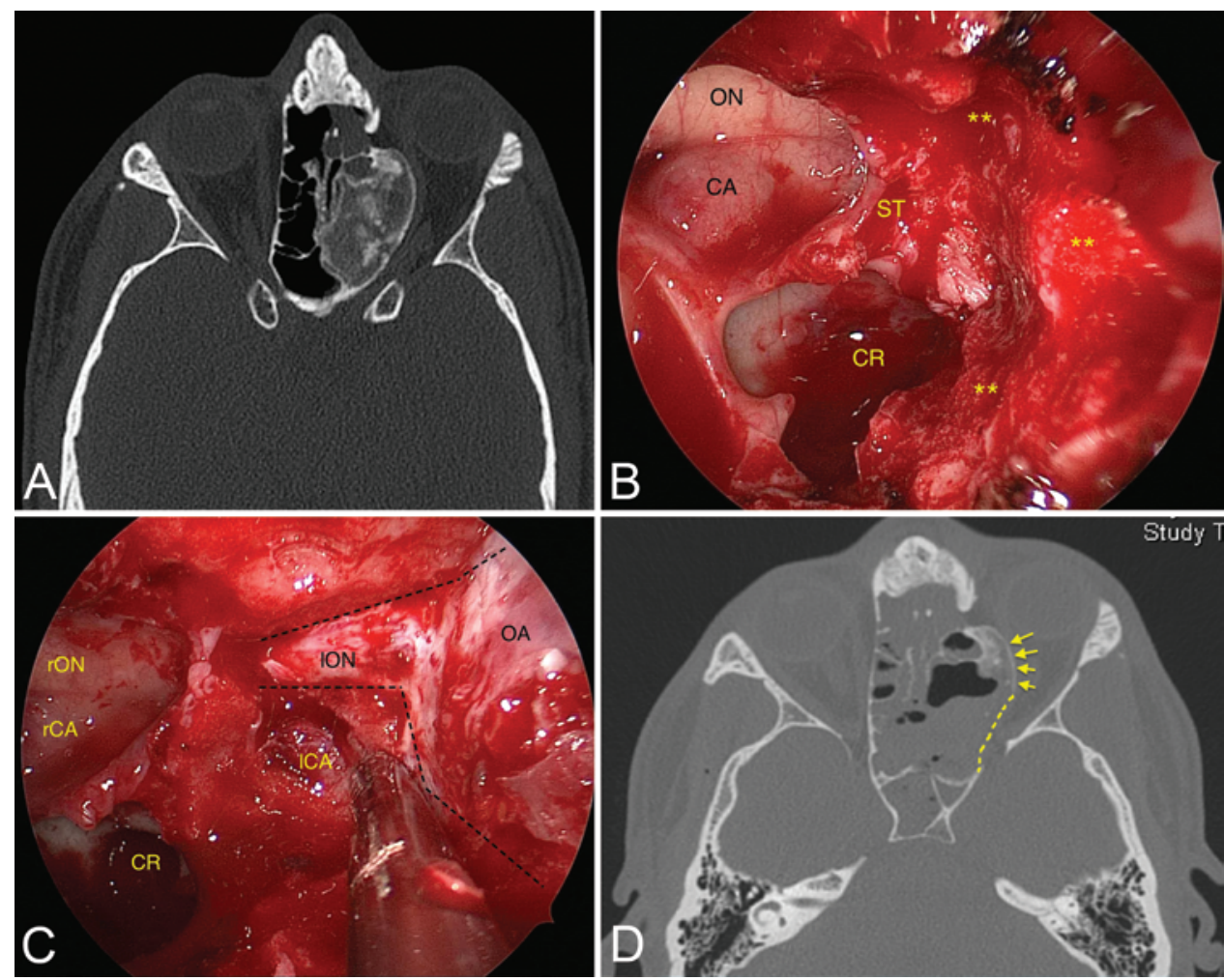

FIG. 2. Case 9. A: Preoperative CT scan demonstrating an ossifying fibroma of the medial orbital apex and left optic canal. B: View after sphenoidotomy and posterior ethmoidectomy via an endoscopic endonasal approach through the left nostril. $\mathrm{CA}=$ right carotid artery; $\mathrm{CR}=$ clival recess; $\mathrm{ON}=$ right optic nerve (contralateral nerve); $\mathrm{ST}$ = sella turcica. Double asterisks indicate tumor of the left orbital apex covering the left optic canal. C: View after tumor drilling and decompression via an endoscopic endonasal approach through the left nostril. CR = clival recess; ICA = left carotid artery; ION = left optic nerve; OA = left orbital apex; rCA = right carotid artery; rON = right optic nerve. D: Postoperative CT scan demonstrating sufficient decompression of the left optic nerve and medial orbital apex (dotted yellow line). Note the remnant on the most anterior medial wall (yellow arrows) requiring regular follow-up.

optic canal fuse to form the periorbita. Typically, the ophthalmic artery lies inferolateral to the optic nerve, but a more medial trajectory is possible and hence should be considered during decompression. The central retinal artery leaves the ophthalmic artery $10 \mathrm{~mm}$ behind the globe.

As seen from below, the optic canal is in direct contact with the lateral sphenoid recess and the most posterior ethmoidal cells. Among these cells are some sphenoethmoidal cells, also known as Onodi cells, which may directly cover the optic canal and must be opened to expose the optic nerve.

\section{Pathophysiology}

From a pathophysiological perspective,${ }^{50,55}$ function of the optic nerve may be altered by a combination of CSF circulation dysfunction, ischemia from arterial injury (ophthalmic artery and central retinal artery), and a direct axoplasmic transport interruption (conduction block, demyelination, degeneration). Edema and hemorrhage inside the nerve are also possible, especially in acute traumatic optic neuropathy. While decompression in acute traumatic optic neuropathy is useful exclusively in the first 3-6 hours, the timing of decompression in chronic optic neuropathy is debatable. Moreover, there is no evidence that

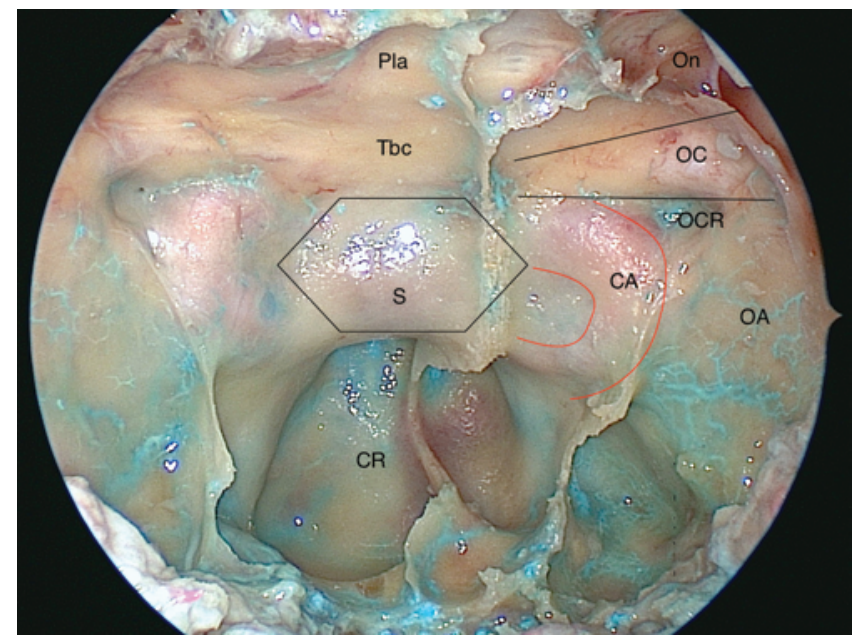

FIG. 3. Endoscopic anatomical view after wide anterior bilateral sphenoidotomy and posterior ethmoidectomy. The sella turcica (S) lies on the midline, limited posteriorly by the clival recess (CR) and anteriorly by the tuberculum sellae ( $\mathrm{Tbc}$ ) and planum sphenoidale (Pla). The sella is bordered laterally by both optic canals $(\mathrm{OC})$ with an anterolateral trajectory going toward the orbital apex $(\mathrm{OA})$ and both internal carotid arteries (CA). OCR = opticocarotid recess; On = Onodi cell. 


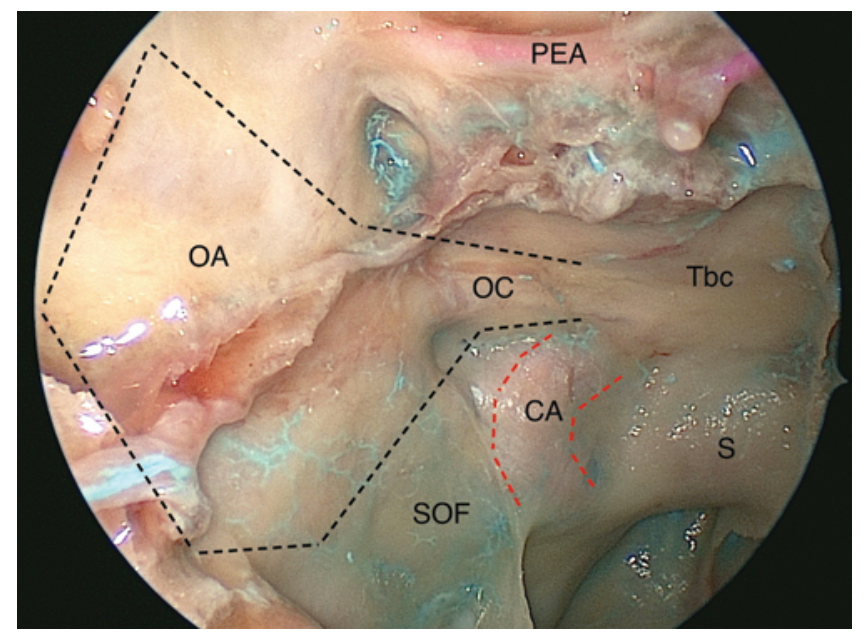

Fig. 4. Endoscopic anatomical view of the right orbital apex demonstrating the relationships of the optic canal $(\mathrm{OC})$ with the posterior ethmoidal artery (PEA) anteriorly and with the superior orbital fissure (SOF) antero-inferiorly. The endoscopic endonasal optic nerve decompression also requires an orbital apex decompression (black dotted lines). Red dotted lines indicate the course of the carotid artery. CA = carotid artery; $\mathrm{OA}=$ orbital apex; $\mathrm{S}=$ sella turcica; $\mathrm{Tbc}=$ tuberculum sellae.

high-dose corticosteroids, particularly as cell membrane stabilizers, are useful in NON.

\section{Patient Evaluation}

A detailed ophthalmological assessment should in-

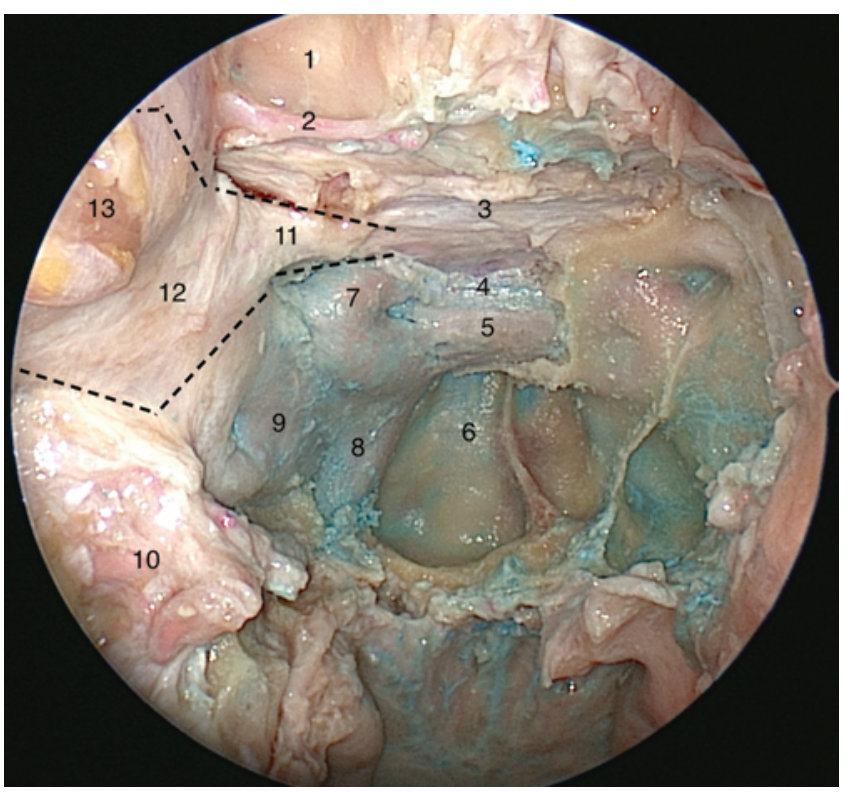

FIG. 5. View after bone removal of the left orbital apex showing the relationships of the left optic nerve with soft tissues. 1, left posterior ethmoidal cell; 2, posterior ethmoidal artery; 3 , dura of the anterior skull base; 4, anterior intercavernous sinus; 5 , sellar dura; 6 , clival recess; 7 , internal carotid artery (parasellar segment); 8 , internal carotid artery (paraclival segment); 9 , superior orbital fissure; 10 , left sphenopalatine artery; 11, left optic nerve sheath; 12 , periorbita; 13 , medius rectus and orbital fat. Black dotted line indicates the orbital apex and optic nerve decompressed.

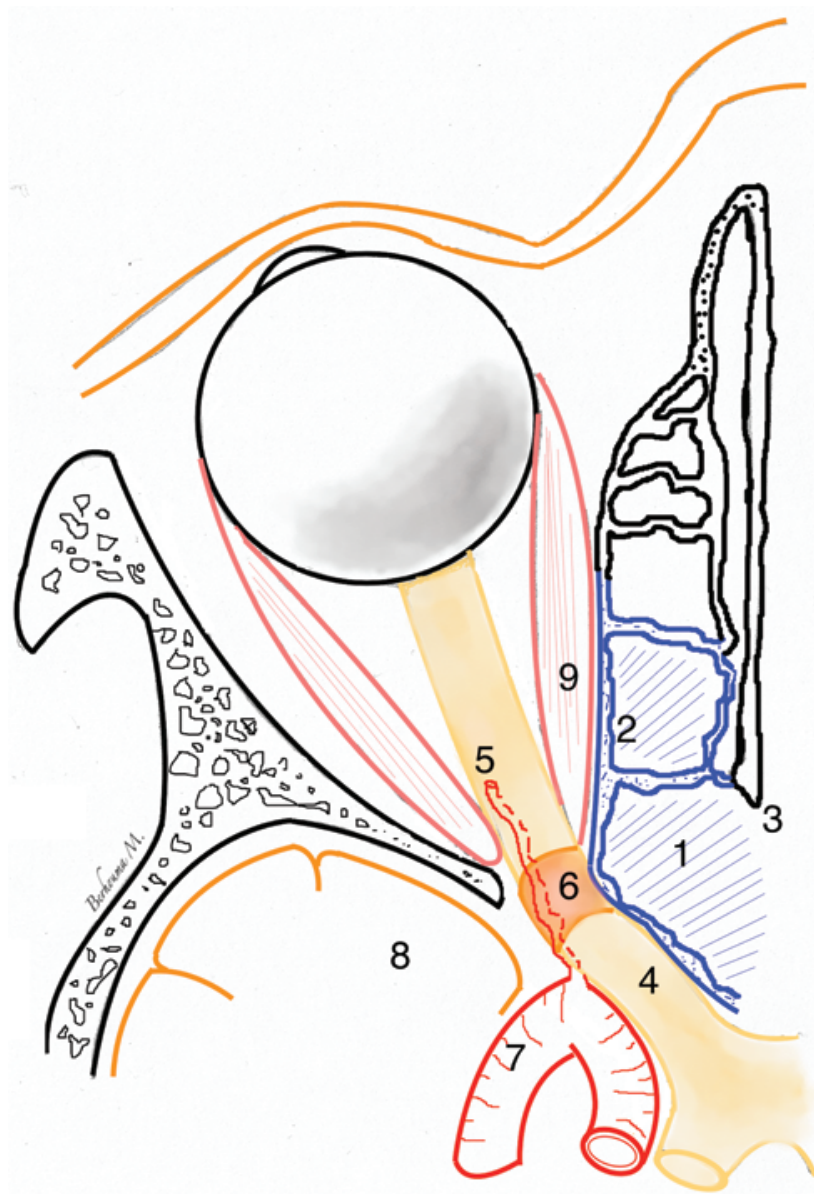

FIG. 6. Axial illustration of the orbital apex. 1, posterior ethmoidal cell; 2 , lamina papyracea; 3 , nasal septum; 4 , optic nerve; 5 , ophthalmic artery; 6 , annulus of Zinn; 7, internal carotid artery; 8 , temporal lobe tip; 9 , medius rectus. Copyright Moncef Berhouma. Published with permission.

clude at least fundoscopic examination, visual acuity evaluation, and computerized visual field testing. As the perception of red is lost first, color vision can also be tested. If the patient is unable to cooperate, monitoring of visually evoked potentials is valuable.

Imaging of the optic canal relies mainly on thinslice CT scanning. This modality accurately shows in 3 anatomical planes (axial, sagittal, and coronal) the pneumatization and septations of the sphenoid sinus and the ethmoidal cells, as well as any uncovered carotid artery. In sphenoorbital meningiomas or dysplasia, CT scanning reveals bone density and thickness. Magnetic resonance imaging should include not only traditional sequences (T1-weighted with or without Gd, T2-weighted) but also a 3D TOF high-resolution sequence. This latter sequence shows very accurately the relationships between the optic nerve and the underlying pathological compressive lesion as well as the position of the ophthalmic artery.

\section{Surgical Technique}

Today, the surgical technique is well standardized with very few variants. $4,16,19,30-34,38,44,60$ The approach is very similar to that used for pituitary surgery; 6,9 therefore, most skull base surgeons are familiar with it. ${ }^{49}$ With the 


\section{Endoscopic endonasal optic nerve decompression}

patient under general anesthesia and orotracheal intubation, his or her head is secured in a 3-pin head holder, and neuronavigation is calibrated with a fusion of CT and MRI data. An intravenous dose of second-generation cephalosporin is administrated. The head is slightly flexed (approximately $30^{\circ}$ ) as for a standard pituitary approach and turned slightly toward the surgeon for a better ergonomic position. The nose is rinsed with iodine ointment, and the abdomen is prepared for graft harvesting in case of CSF leakage requiring skull base reconstruction. Both nasal fossae are decongested using cotton soaked in a solution of lidocaine mixed with adrenalin. The draping should leave both eyes exposed in the operative field so that evaluation of the globes can be performed if required intraoperatively. An adjustable self-retaining holding arm is secured to the operating table to be used at specific phases of the surgical procedure. The nasal phase is usually performed with a $0^{\circ}$ rigid endoscope in the nostril ipsilateral to the optic neuropathy. A middle turbinectomy and a posterior ethmoidectomy are performed before opening the anterior wall of the sphenoid sinus. All septa within the sphenoid sinus are widely opened to allow optimal visualization of exocranial skull base, that is, the sella turcica between the parasellar carotid arteries and the optic canals as well as the opticocarotid recesses (Fig. 3). Toward the lateral sphenoid recesses, the medial orbital apex can be recognized (lamina papyracea). In some patients, carotid arteries and/ or optic nerves are not covered by bone. Special attention is required to identify any sphenoethmoidal cell (Onodi cell) that needs to be opened carefully to expose the optic canal. Neuronavigation may be very helpful in a nonpneumatized sphenoid sinus requiring time-consuming bone drilling. At this point, a long rigid endoscope is secured within the self-retaining endoscope holder. The decompression progresses from lateral to medial beginning at the level of the lamina papyracea, which is usually very thin and easily resected with a spoon curette or a spatula. Special care is taken to keep the periorbita intact to avoid the bulge of the orbital fat within the field. Decompression progresses to the optic canal, which is drilled using either a rotating tip or an ultrasonic bone cutter always under generous irrigation to limit heat diffusion to the optic nerve. Once the bone of the optic canal is thinned, it is outfractured with a blunt spatula away from the optic nerve. This bony decompression should reach at least $180^{\circ}$ around the optic nerve and optimally up to $270^{\circ}$ (superomedial, medial, and inferomedial aspects). Pulsations of the optic nerve signal good decompression. Opening the optic nerve sheath is very controversial and exposes the patient to CSF leakage as well as the ophthalmic artery to injury and should therefore be reserved for very specific cases (for example, idiopathic intracranial hypertension).

If a tumor is present, it can be resected or biopsied. At the end of the procedure, a thin layer of biological glue is sprayed on the optic nerve and the carotid artery to optimize hemostasis and protect these structures from the sphenoid mucosa. No nasal packing is needed.

\section{Postoperative Management}

A preliminary visual assessment is performed in the recovery room. The role of perioperative steroids is still debated. Vision is monitored, as is any hemorrhagic nasal discharge during the first 3 postoperative days. Daily nasal saline sprays are useful for accelerating mucosal healing and for patient comfort. Patients are usually discharged after 4-5 days. We propose performing an endoscopic examination with a local anesthetic to verify healing, as well as a complete visual assessment, 1 month after surgery. A control CT scan is also obtained to assess the extent of decompression.

\section{Indications for and Timing of Surgery}

The role of endoscopic endonasal decompression is debatable for traumatic optic neuropathy, mainly because of the high rate of spontaneous improvements without intervention; however, this natural resolution is not expected in nontraumatic chronic cases..$^{5,50,57}$ Our positive visual results in the short term in the present study, despite the study's retrospective nature, limited number of patients, and heterogeneous series, reflect an obvious benefit from a minimally invasive technique with very low morbidity. The technique can be proposed for diverse pathologies (Table 3) threatening the optic nerve(s) in their intracanalicular portion (Fig. 7).

Only a few studies dealing with endoscopic endonasal decompression for NON are reported in the literature. ${ }^{5,35,41,45}$ Pletcher and Metson described 10 decompressions in 7 patients with various underlying pathologies similar to those in our series, with a good visual outcome for $70 \%$ of the patients. ${ }^{41}$ Studies dealing with idiopathic intracranial hypertension involve opening of the optic nerve sheath, raising the risk of CSF leakage.

\section{Conclusions}

Our preliminary results confirm the potential benefits of endoscopic endonasal optic nerve decompression for nontraumatic neuropathies. This minimally invasive technique allows tissue sampling and/or tumor removal if indicated during the same procedure. Optic nerve decompression must be considered early in the course of a disease before the onset of optic nerve atrophy. Nevertheless, given the variety of possible underlying pathologies, it is important to not draw premature conclusions about any recommendation in the absence of randomized studies and more homogeneous series.

\section{TABLE 3: Potential indications for endoscopic endonasal optic nerve and orbital apex decompression}

optic nerve sheath meningioma
osteopetrosis
fibrous dysplasia
endocrine orbitopathy
orbital apex tumors
medial orbital tumors
mucocele
idiopathic intracranial hypertension
cavernous sinus tumors w/ extension to optic canal
sphenoorbital meningioma
cortico-resistant inflammatory optic \&/or orbital disease

optic nerve sheath meningioma

osteopetrosis

fibrous dysplasia

idiopathic intracranial hypertension

cortico-resistant inflammatory optic \&/or orbital disease 

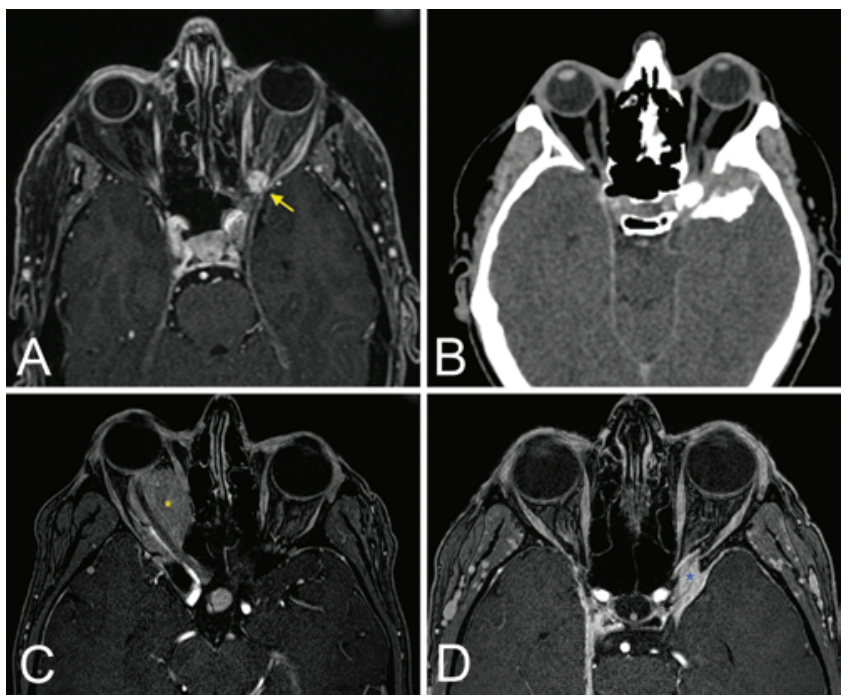

FIG. 7. Examples of pathologies amenable to endoscopic endonasal optic nerve decompressions. A: Left optic nerve sheath meningioma (Case 6). B: Left sphenoorbital meningioma (Case 11). C: Right orbital apex meningioma (Case 7). D: Left optic nerve meningioma (Case 4).

\section{Disclosure}

The authors report no conflict of interest concerning the materials or methods used in this study or the findings specified in this paper.

Author contributions to the study and manuscript preparation include the following. Conception and design: Berhouma, Jouanneau. Acquisition of data: all authors. Analysis and interpretation of data: Berhouma. Drafting the article: Berhouma, Jouanneau. Critically revising the article: all authors. Reviewed submitted version of manuscript: all authors. Approved the final version of the manuscript on behalf of all authors: Berhouma. Administrative/technical/material support: Berhouma. Study supervision: Berhouma, Jouanneau.

\section{References}

1. Abuzayed B, Tanriover N, Gazioglu N, Eraslan BS, Akar Z: Endoscopic endonasal approach to the orbital apex and medial orbital wall: anatomic study and clinical applications. J Craniofac Surg 20:1594-1600, 2009

2. Aldea S, Bică D, Gobej I, Bennis S, Baussart B, Mireau E, et al: Bilateral orbital and optic nerve endoscopic endonasal decompression for nonspecific inflammatory orbital disease: case report. J Neurol Surg A Cent Eur Neurosurg 74 Suppl 1:e133-e135, 2013

3. Amit M, Fliss DM, Gil Z: Fibrous dysplasia of the sphenoid and skull base. Otolaryngol Clin North Am 44:891-902, vii-viii, 2011

4. Anand VK, Sherwood C, Al-Mefty O: Optic nerve decompression via transethmoid and supraorbital approaches. Op Tech Otolaryngol Head Neck Surg 2:157-166, 1991

5. Attia M, Kandasamy J, Jakimovski D, Bedrosian J, Alimi M, Lee DLY, et al: The importance and timing of optic canal exploration and decompression during endoscopic endonasal resection of tuberculum sella and planum sphenoidale meningiomas. Neurosurgery 71 (1 Suppl Operative):58-67, 2012

6. Berhouma M, Messerer M, Jouanneau E: Occam's razor in minimally invasive pituitary surgery: tailoring the endoscopic endonasal uninostril trans-sphenoidal approach to sella turcica. Acta Neurochir (Wien) 154:2257-2265, 2012

7. Berhouma M, Messerer M, Jouanneau E: [Shifting paradigm in skull base surgery: roots, current state of the art and future trends of endonasal endoscopic approaches.] Rev Neurol (Paris) 168:121-134, 2012 (Fr)

8. Bleier BS, Healy DY Jr, Chhabra N, Freitag S: Compartmental endoscopic surgical anatomy of the medial intraconal orbital space. Int Forum Allergy Rhinol 4:587-591, 2014

9. Carrau RL, Kassam AB, Snyderman CH: Pituitary surgery. Otolaryngol Clin North Am 34:1143-1155, ix, 2001

10. Cebula H, Lahlou A, De Battista JC, Debry C, Froelich S: [Endoscopic approaches to the orbit.] Neurochirurgie 56:230235, 2010 (Fr)

11. Chen C, Selva D, Floreani S, Wormald PJ: Endoscopic optic nerve decompression for traumatic optic neuropathy: an alternative. Otolaryngol Head Neck Surg 135:155-157, 2006

12. Chu EA, Miller NR, Lane AP: Selective endoscopic decompression of the orbital apex for dysthyroid optic neuropathy. Laryngoscope 119:1236-1240, 2009

13. De Ganseman A, Lasudry J, Choufani G, Daele J, Hassid S: Intranasal endoscopic surgery in traumatic optic neuropathythe Belgian experience. Acta Otorhinolaryngol Belg 54: $175-177,2000$

14. Fu JD, Song WX, Zhang JL: [Endoscopic decompression of optic canal.] Zhonghua Yi Xue Za Zhi 85:3123-3125, 2005 (Chinese)

15. Gupta AK, Ganth MGR, Gupta A: Modified endoscopic optic nerve decompression in idiopathic intracranial hypertension. J Laryngol Otol 117:501-502, 2003

16. Hart CK, Theodosopoulos PV, Zimmer LA: Anatomy of the optic canal: a computed tomography study of endoscopic nerve decompression. Ann Otol Rhinol Laryngol 118:839-844, 2009

17. Haruna S, Tukidate T, Konno W, Fukami S, Nakajima I: Transnasal endoscopic surgery for benign orbital tumors. Auris Nasus Larynx 40:227-230, 2013

18. Hathiram BT, Khattar VS, Sonawane HP, Watve PJ: Traumatic optic neuropathy-our experience. Indian J Otolaryngol Head Neck Surg 62:229-235, 2010

19. Horiguchi K, Murai H, Hasegawa Y, Mine S, Yamakami I, Saeki N: Endoscopic endonasal trans-sphenoidal optic nerve decompression for traumatic optic neuropathy-technical note. Neurol Med Chir (Tokyo) 50:518-522, 2010

20. Jiang RS, Hsu CY, Shen BH: Endoscopic optic nerve decompression for the treatment of traumatic optic neuropathy. Rhinology 39:71-74, 2001

21. Kasperbauer JL, Hinkley L: Endoscopic orbital decompression for Graves' ophthalmopathy. Am J Rhinol 19:603-606, 2005

22. Koc K, Anik I, Altintas O, Ceylan S: Endoscopic optic nerve decompression for idiopathic intracranial hypertension in two cases: case report. Minim Invasive Neurosurg 51:72-75, 2008

23. Kong DS, Shin HJ, Kim HY, Chung SK, Nam DH, Lee JI, et al: Endoscopic optic canal decompression for compressive optic neuropathy. J Clin Neurosci 18:1541-1545, 2011

24. Kountakis SE, Maillard AA, Urso R, Stiernberg CM: Endoscopic approach to traumatic visual loss. Otolaryngol Head Neck Surg 116:652-655, 1997

25. Lal P, Thakar A, Tandon N: Endoscopic orbital decompression for Graves' orbitopathy. Indian J Endocrinol Metab 17:265270,2013

26. Leonard DW, Bolger WE: Minimally invasive approach for biopsy of an optic nerve sheath tumor. Otolaryngol Head Neck Surg 120:776-779, 1999

27. Levy J, Puterman M, Lifshitz T, Marcus M, Segal A, Monos T: Endoscopic orbital decompression for Graves' ophthalmopathy. Isr Med Assoc J 6:673-676, 2004

28. Li H, Zhou B, Shi J, Cheng L, Wen W, Xu G: Treatment of traumatic optic neuropathy: our experience of endoscopic optic nerve decompression. J Laryngol Otol 122:1325-1329, 2008

29. Li HB, Shi JB, Cheng L, Yun O, Xu G: Salvage optic nerve 
decompression for traumatic blindness under nasal endoscopy: risk and benefit analysis. Clin Otolaryngol 32:447-451, 2007

30. Li J, Wang J, Jin X, Qiu Y: [Endoscopic anatomy research related to transsphenoidal optic nerve decompression.] Lin Chung Er Bi Yan Hou Tou Jing Wai Ke Za Zhi 23:52-54, 2009 (Chinese)

31. Li J, Wang J, Jing X, Zhang W, Zhang X, Qiu Y: Transsphenoidal optic nerve decompression: an endoscopic anatomic study. J Craniofac Surg 19:1670-1674, 2008

32. Li Y, Wu W, Xiao Z, Peng A: Study on the treatment of traumatic orbital apex syndrome by nasal endoscopic surgery. Eur Arch Otorhinolaryngol 268:341-349, 2011

33. Liu JK, Christiano LD, Patel SK, Tubbs RS, Eloy JA: Surgical nuances for removal of tuberculum sellae meningiomas with optic canal involvement using the endoscopic endonasal extended transsphenoidal transplanum transtuberculum approach. Neurosurg Focus 30(5):E2, 2011

34. Locatelli M, Caroli M, Pluderi M, Motta F, Gaini SM, Tschabitscher M, et al: Endoscopic transsphenoidal optic nerve decompression: an anatomical study. Surg Radiol Anat 33:257262,2011

35. Lund VJ, Rose GE: Endoscopic transnasal orbital decompression for visual failure due to sphenoid wing meningioma. Eye (Lond) 20:1213-1219, 2006

36. Luxenberger W, Stammberger H, Jebeles JA, Walch C: Endoscopic optic nerve decompression: the Graz experience. Laryngoscope 108:873-882, 1998

37. Maurer J, Hinni M, Mann W, Pfeiffer N: Optic nerve decompression in trauma and tumor patients. Eur Arch Otorhinolaryngol 256:341-345, 1999

38. Murchison AP, Rosen MR, Evans JJ, Bilyk JR: Endoscopic approach to the orbital apex and periorbital skull base. Laryngoscope 121:463-467, 2011

39. Patrocínio JA, Patrocínio LG, Júnior FBR, da Cunha AR: Endoscopic decompression of the optic nerve in pseudotumor cerebri. Auris Nasus Larynx 32:199-203, 2005

40. Peng A, Li Y, Hu P, Wang Q: Endoscopic optic nerve decompression for traumatic optic neuropathy in children. Int $\mathbf{J}$ Pediatr Otorhinolaryngol 75:992-998, 2011

41. Pletcher SD, Metson R: Endoscopic optic nerve decompression for nontraumatic optic neuropathy. Arch Otolaryngol Head Neck Surg 133:780-783, 2007

42. Pletcher SD, Sindwani R, Metson R: Endoscopic orbital and optic nerve decompression. Otolaryngol Clin North Am 39: 943-958, vi, 2006

43. Pribitkin EA, McJunkin J, Kung B, Carrasco JR, Bilyk JR, Savino PJ: Technique selection for orbital decompression: combined endoscopic and transconjunctival versus combined endoscopic and transantral approach. Ear Nose Throat J 88: E12, 2009

44. Rastelli MM Jr, Pinheiro-Neto CD, Fernandez-Miranda JC, Wang EW, Snyderman CH, Gardner PA: Application of ultrasonic bone curette in endoscopic endonasal skull base surgery: technical note. J Neurol Surg B Skull Base 75:90-95, 2014

45. Sencer A, Akcakaya MO, Basaran B, Yorukoglu AG, Aydoseli A, Aras Y, et al: Unilateral endoscopic optic nerve decompression for idiopathic intracranial hypertension: a series of ten patients. World Neurosurg [epub ahead of print], 2014

46. Sia DIT, Chan WO, Wormald PJ, Davis G, Selva D: Decompression of benign orbital apex lesion via medial endoscopic approach. Orbit 31:344-346, 2012

47. Sieśkiewicz A, Łysoń T, Mariak Z, Rogowski M: [Endoscopic decompression of the optic nerve in patients with post-traumatic vision impairment.] Klin Oczna 110:155-158, 2008 (Polish)
48. Sieśkiewicz A, Łysoń T, Rogowski M, Mariak Z: [Endoscopic transnasal approach for optic nerve decompression.] Otolaryngol Pol 62:295-299, 2008 (Polish)

49. Snyderman C, Kassam A, Carrau R, Mintz A, Gardner P, Prevedello DM: Acquisition of surgical skills for endonasal skull base surgery: a training program. Laryngoscope 117:699705,2007

50. Song Y, Li H, Ma Y, Li W, Zhang X, Pan X, et al: Analysis of prognostic factors of endoscopic optic nerve decompression in traumatic blindness. Acta Otolaryngol 133:1196-1200, 2013

51. Tang IP, Prepageran N, Subrayan V, Tajunisah I: Endoscopic orbital decompression for optic neuropathy in thyroid ophthalmopathy. Med J Malaysia 63:337-338, 2008

52. Thaker A, Tandon DA, Mahapatra AK: Surgery for optic nerve injury: should nerve sheath incision supplement osseous decompression? Skull Base 19:263-271, 2009

53. Wang DH, Zheng CQ, Qian J, Barr JJ, Anderson AG Jr: Endoscopic optic nerve decompression for the treatment of traumatic optic nerve neuropathy. ORL J Otorhinolaryngol Relat Spec 70:130-133, 2008

54. Wang X, Li XS, Wang WC: [Transnasal endoscopic optic canal decompression for traumatic optic neuropathy without light reception.] Zhonghua Er Bi Yan Hou Tou Jing Wai Ke Za Zhi 42:625-626, 2007 (Chinese)

55. Xie MQ, Long Z, Li ZH, Zhang HZ, Yang QT, Liu X, et al: [Timing of operation and therapeutic effect of endoscopic optic nerve decompression for traumatic optic neuropathy.] Zhonghua Er Bi Yan Hou Tou Jing Wai Ke Za Zhi 44:197202, 2009 (Chinese)

56. Xu G, Jiang HY, Xu R, Shi JB, Wen WP: [Surgical treatment for bilateral traumatic optic neuropathy through intranasal endoscopic approach.] Zhonghua Er Bi Yan Hou Tou Jing Wai Ke Za Zhi 41:430-432, 2006 (Chinese)

57. Xu R, Chen F, Zuo K, Ye X, Yang Q, Shi J, et al: Endoscopic optic nerve decompression for patients with traumatic optic neuropathy: is nerve sheath incision necessary? ORL J Otorhinolaryngol Relat Spec 76:44-49, 2014

58. Yang QT, Zhang GH, Liu X, Ye J, Li Y: The therapeutic efficacy of endoscopic optic nerve decompression and its effects on the prognoses of 96 cases of traumatic optic neuropathy. J Trauma Acute Care Surg 72:1350-1355, 2012

59. Zhang H, Zhang D, Chen X: [Transnasal optic nerve decompression for optic nerve injury.] Lin Chuang Er Bi Yan Hou Ke Za Zhi 19:165-167, 2005 (Chinese)

60. Zhang J, Liao J, Yang Y, Lu Q, Hu J, Jiang T, et al: [Applied anatomy study of optic canal by transnasal endoscopy.] Lin Chung Er Bi Yan Hou Tou Jing Wai Ke Za Zhi 23:346348, 2009 (Chinese)

61. Zuo KJ, Shi JB, Wen WP, Chen HX, Zhang XM, Xu G: [Transnasal endoscopic optic nerve decompression for traumatic optic neuropathy: analysis of 155 cases.] Zhonghua Yi Xue Za Zhi 89:389-392, 2009 (Chinese)

Manuscript submitted June 12, 2014.

Accepted July 22, 2014.

Please include this information when citing this paper: DOI: 10.3171/2014.7.FOCUS14303.

Address correspondence to: Moncef Berhouma, M.D., M.Sc., Skull Base Surgery Unit, Department of Neurosurgery B, Pierre Wertheimer Neurological and Neurosurgical Hospital, Hospices Civils de Lyon, 59 Boulevard Pinel, 69394 Lyon Cedex 03, France. email: berhouma.moncef@gmail.com. 